\title{
Scope and limits of the obligations of health workers during a pandemic
}

\begin{abstract}
The obligation to provide services, by health professionals, in a pandemic such as that caused by the SARS-Cov-2 virus is not unlimited; it is essential to take into account the risk factors of health personnel, in the event of absence and / or death, the cost benefit, the consideration of their vulnerability as being human and social being susceptible to being infected and infecting their family nucleus. That's why it's important to know that medicine is a humanitarian profession with deontological demands that transcend the moral plane.
\end{abstract}

Keywords: health professionals, pandemic, human, social, deontological demands
Volume 5 Issue 2 - 202I

\author{
Jennifer Hincapie Sanchez \\ Associate Professor "C" of the Faculty of Medicine, National \\ Autonomous University of Mexico (UNAM), Mexico
}

\begin{abstract}
Correspondence: Jennifer Hincapie Sanchez, Associate Professor "C" of the Faculty of Medicine of the National Autonomous University of Mexico (UNAM), Coordinator of the Institutional Ethics and Bioethics Program FACMED, Responsible for the Field of Knowledge of Bioethics of the Master's and Doctorate Program in Medical, Dental and Medical Sciences Health UNAM, Mexico, Email jhincapie@unam.mx
\end{abstract}

Received: February 13, 2021 | Published: March 10, 202 |

\section{Mini review}

The pandemic caused by the SARS-Cov-2 virus has reached proportions not seen in the recent history of humanity, the number of infections continues to grow exponentially with more than 80 million cases (reported) to date, ${ }^{1}$ thus generating a strong impact of social, economic, cultural order and especially in health systems globally. Much has been discussed and written regarding the lack of planning of the states, in matters of public health to confront a health crisis of these characteristics, of the exacerbation of the imbalance between the demand for medical, economic and social assistance and the capacities of the government to respond to the essential needs of the population and even the inability to implement effective measures to contain the spread of the virus.

Demanding a change in the paradigm of the "established order" that societies held until a few months ago, that is, the way in which Human beings are interrelated, how daily tasks are carried out, the ways and means of work, the configuration of educational processes, among many others. This situation raises the urgent need for a scaffolding that offers effective and immediate solutions. The objective of this document is to reflect on the complex situation that health professionals go through in the face of a health crisis situation such as that caused by SARS-Cov-19, with a view to humanizing / raising awareness of the exercise of medicine.

The practice of medicine has undergone great changes in a short time, and with it the ethical reflections associated with it. Medical care in times of health crisis raises dilemmas that add to the excessive problems. This context is ideal for both bioethics and medical ethics to raise their voices to invite this dialogue from a humanistic perspective, so that each individual can offer everything in their power to overcome the pandemic.

The data obtained on October 10, 2020 from the portal COVID-19 Dashboard by the Center for Systems Science and Engineering (CSSE) at Johns Hopkins University $(\mathrm{JHU})^{2}$ they allow us to assess the complexity of the health situation at a global level, where, according to statistics, the excessive increase in cases of contagion, the number of deaths and the countries affected by COVID-19 is notable. This allows us to infer that there is not, up to now, a state that has the possibilities of proposing a public health policy that mitigates the effects of the virus, despite the warnings issued by international epidemiologists. ${ }^{3}$

Faced with a situation like the one that is currently evident, it is consequential to rethink the priorities of a society, showing that it is necessary to change, by way of example, the ultimate goal of medicine, which after great efforts in promoting the humanistic vision leaving aside the restoration of health, the prevention and eradication of diseases, care centered on the patient and his family; for a perspective of immediate care ready to save as many lives as possible, with all the technical and scientific means available to health professionals.

There is no doubt that the states are making the best effort to achieve care for the largest number of patients with COVID-19, which should not translate into the limitation of the actions that are carried out to attend to the other clinical pictures that do not stop appearing due to the pandemic, however these efforts could become insufficient and trigger deaths due to lack of care and / or resources to provide it, a number of deaths that are not recorded as one of the adverse effects of the pandemic.

Against this background, it is worth taking up some basic concepts, which will allow us to have a frame of reference for reflection and subsequent awareness of the scope and limits of the medical profession. When speaking of a profession that is in charge of caring for the other and restoring the well-being of people, it is necessary to connect with the idea of responsibility, which according to the Dictionary of the Spanish Language is the "existing capacity in all active subject of law to recognize and accept the consequences of an act carried out freely "4 Ferrater Mora, for his part, affirms "It is said of a person who is responsible when he is obliged to answer for his own acts". 5

However, the form of responsibility that the practice of medicine brings has particular edges: "Professional Medical Responsibility. The obligation that doctors have to repair and satisfy the consequences of voluntary and involuntary acts, omissions and errors, even, within certain limits, committed in the exercise of their profession". ${ }^{6}$ 
Health constitutes one of the legal assets that must be protected by the Political Constitutions of the states, which, in recognition of Human Rights, ensure access to health services. In this way, it can be seen that there are several elements that are part of an adequate development of the medical professional practice, the constant commitment to scientific and technical updating, their performance in the establishment of the doctor - patient / family and doctor - team of health, which constitute one of the fundamental pillars of the process of restoring health, and adherence to the legal framework that ensures health as a legal asset. This means that any damage (by acts or omissions) that occurs to the health of a person must be punished and the damage repaired.

Returning to the idea of the health crisis, it is necessary to identify that the health crisis brings with it an imbalance in the possibilities of providing clinical care to the demand of the population, that is, it is evident that a considerable number of people require clinical care, while the possibilities of supply in many of the health systems at the global is limited.

To this we add the scarcity of personal protection resources, the limitation of resources to provide adequate care, the shortage of beds in intensive care units and respirators, of drugs that work effectively as a treatment, of clinical personnel with adequate training to treat a disease that manifests itself in a multifactorial manner, the aggressions of citizens towards health personnel ${ }^{7}$ and workers in the health context, exposure to a pathogen whose natural history is not yet known for sure, nor its evolution and the total of the effects that it may bring, nor an effective treatment, much less a vaccine. At this point it is fair to question:

\section{Can healthcare professionals refuse to treat suspected COVID-I 9 patients?}

This is a question that can be answered from various perspectives. One is the deontological perspective that obliges any person with a profession or trade to provide services in accordance with their professional training and capacity, as an example we will use the Code of Medical Deontology of the Organization of Collegiate Medical Ethics of Spain, which in its Chapter II General Principles, Article 5.

I. The medical profession is at the service of the human being and of society. Respecting human life, the dignity of the person, and caring for the health of the individual and the community are the primary duties of the physician.

II. The doctor must attend all patients with the same diligence and solicitude, without any discrimination.

III. The main loyalty of the doctor is the one he owes to his patient and the health of the latter must come before any other convenience. The doctor cannot refuse assistance for fear that the patient's illness or circumstances pose a personal risk.

IV. The doctor will never intentionally harm the patient. It will attend you with prudence and competence, avoiding any unjustified delay in your assistance. ${ }^{8}$

The deontology of a profession must be understood from the dimension of the role that a profession plays in a social context and the way in which those who belong to it must respond in certain situations, hence the obligations of the professional exercise are established through a deliberative process which is reflected in the ethical codes, also known as codes of ethics of the professions. Despite this, the obligation to provide health care in a pandemic such as that caused by the SARS-Cov-2 virus is not explicitly described in these codes and it is more moral arguments that invite us to identify this obligation.
The obligation to provide services, by health professionals, is not unlimited; For this reason, it is essential to take into account the risk factors of health personnel, the probabilities and possibilities of replacing them immediately, in the event of absence and / or death, the cost benefit, the consideration of their vulnerability as being human and social being susceptible to being infected and infecting their family nucleus, as is the case of people in the health sector who are in the front line developing tasks with a high degree of exposure and in conditions of high demand, to the point that healthcare centers close because all staff are infected in some European countries represent almost $20 \%$ of the total confirmed infections, ${ }^{9}$ and even the increase in the deaths of health professionals from COVID-19. ${ }^{10} \mathrm{~A}$ second possible answer is located in the idea that medicine is a humanitarian profession with deontological demands that transcend the moral plane, W. Jaeger, in Paideia, states that:

"The doctor appears here as the representative of a special culture of the highest methodical refinement and is, at the same time, the embodiment of an exemplary professional ethic by projecting knowledge on an ethical purpose of a practical nature, which is therefore invoked constantly to inspire confidence in the creative purpose of theoretical knowledge regarding the construction of human life ". ${ }^{11}$

This is the type of conceptualization that society in general has of health professionals, beings endowed with an inalienable ethical burden, who put their profession before their development as a biopsychosocial being.

ED Pellegrino affirms that there are "three constitutive factors of medicine that necessarily make it a moral undertaking, which imposes serious collective responsibilities on the shoulders of those who practice it: 1) the nature of the disease; 2) the community nature of medical knowledge (these never constitute private property, they are patrimony of humanity); 3) the professional oath". ${ }^{12}$

In the proposal of medical ethics promulgated by Edmund Pellegrino and David C. Thomasma in texts such as A philosophical Basis of Medical Practice (1980) and The Virtues in Medical Practice (1993), it requires that health professionals and in a timely manner Doctors are virtuous beings, willing to offer their knowledge for the benefit of patients and not for their financial gain or good name; in short, they do not take advantage of the vulnerability of the patient.

The ethics of virtues allows health professionals to achieve excellence based on the Aristotelian principle of improving each time an action is performed, if a reading between the lines is achieved, the demand for the ethics of virtues is greater to the simple fulfillment of the deontological rules, because it requires an emptying of the being in the exercise of the medical profession, acting in a straight way in all situations.

With this idea arranged as medical ethics, the authors propose to define a table of virtues that should be required of health professionals, these virtues, although they are the foundation of Christianity, permeate across society and have been converted into what could be thought of as a minimum ethic, for those who take care of the health of the other. By way of enunciation, the table of virtues is arranged as follows:

\section{Fidelity to promise}

\section{Benevolence}

III. Abnegation

IV. Compassion 


\section{Intellectual Humility}

VI. Justice

\section{Prudence}

With the cultivation of virtues as the main axis of the health profession, the integrity of the medical act is ensured. Today the common denominator of the population thinks of doctors as virtuous beings, "heroes in white coats" who must deny their own humanity for the restitution of the health of another, who behave as a being full of the spirit of Christ, who exercises with scientific objectivity and forgetting the responsibility that as an individual has in society, so the doctor must throw himself into his profession, he must forget his being as a parent, friend or member of a society to dedicate himself to his profession, to provide urgent medical attention during disasters.

This obligation won per se persists even in situations of risk in which even the health or lives of the doctors are involved. Ultimately what the international ethical framework is telling us is that doctors have a deontological and moral obligation to throw themselves into their profession.

The aforementioned arguments do not allow the image of morally superior beings to be deconstructed, and we make them part of this collective vulnerability that assists us all based on COVID-19, health professionals are also members of communities, fathers, mothers, children, grandchildren, grandparents, hypertensive, diabetic, asthmatic, elderly, young, pregnant, who in addition to their professional obligation have social responsibilities with their environment, in other words, it is lost sight that doctors get sick, die, they can be infected, since apparently said contagion of this disease in a clinical context is not linked only to the neglect of lack of hygiene, it depends on other factors such as the scarcity of resources.

Although health professionals must assume the risks inherent in their profession, from a legal perspective of the profession, there is no possibility of refusing from a personal level to provide care to a patient who represents an eminent risk for the treating physician, such as mentioned in article 229 of the Federal Criminal Code, ${ }^{13}$ that is to say, that the denial of the fulfillment of the labor duty for reasons of preservation of life itself, is regulated by Mexican laws and even by international instruments such as the International Code of Medical Ethics, the Declaration of Geneva, among others.

Although it is true that doctors, nursing staff, laboratory personnel, health personnel and other professions and trades that complement clinical teams, as human beings have the possibility of demanding respect for Human Rights (the clarification seems negligible, However, in a context where clinical actions with good results are attributed to metaphysical entities and adverse results to medical error, it is worth clarifying), society does not accept this type of "flaws" and perhaps it is this position that explain, but do not justify physical attacks on health professionals, criticism of burnout or moral stress.

The Charter of Physicians' Rights, ${ }^{14}$ presented as the result of a systematic documentary review carried out in 2001, by the National Commission of Medical Arbitration (CONAMED), who, upon confirming the Charter of the Rights of Patients, noted a strong absence from the other party. Prepared on the basis of General Health Law and its Regulations of the General Health Law regarding the provision of medical care services and NOM-168SSA1-1998, of the Clinical Record it is little known. However, it provides an understanding of the scope of the medical profession, in 10 statements that indicate:

I. Exercise the profession freely and without pressure of any kind. The physician has the right to have his clinical judgment (his conclusions about the diagnosis and treatment) and your freedom to prescribe or indicate treatments; as well as their probable decision to decline or reject the care of a patient, provided that such aspects are based on ethical, scientific and normative principles.

II. Work in appropriate and safe facilities that guarantee their practice professional.

III. Have at your disposal the resources your professional practice requires. Is a Right of the doctor, to receive from the establishment where he provides his service: suitable personnel, as well as equipment, instruments and necessary supplies, in accordance with the service he provides.

IV. Refrain from guaranteeing results in medical care. The physician has the right not to make conclusive judgments about the expected results of medical care.

$V$. Receive respectful treatment from patients and their families, as well as from personnel related to your professional work. In addition, the doctor has the right to receive complete, truthful and timely information related to the patient's health status.

VI. Have access to continuing medical education and be considered equally opportunities for their professional development, in order to stay updated.

VII. Have access to research and teaching activities in the field of their profession.

VIII. Partner to provide your professional interests. The doctor has the right to associate in organizations, associations and schools for their professional development, in order to promote the improvement of their members and monitor the proper professional practice, in accordance with the provisions of the law.

IX. Safeguard your professional prestige. The doctor has the right to defend his professional prestige and that his information is treated with privacy if there is a probable controversy, and where appropriate to claim compensation for the damage caused.

$X$. Receive remuneration for the services provided. The doctor has the right to be paid for the professional services he provides, according to his contract, labor condition or what was agreed with the patient.

From this letter it is essential to rescue two essential points that are blurred in the context of the pandemic, due to the main interest of saving lives, the first says: " 2 . Work in appropriate and safe facilities that guarantee their professional practice: The doctor has the right to have workplaces and facilities that comply with safety and hygiene measures, including those established by law, in accordance with the characteristics of the service to grant." And "3. Have at your disposal the resources your professional practice requires. ${ }^{15}$

In such a way that if a doctor does not have the basic equipment to generate a biological protection barrier for a virus for which there are unknown ways of eradication and effective treatment, this obligation could be blurred. However, there are cases without being officially reported where doctors and nurses who bought their own supplies in order not to put their lives at risk. Of course, it is necessary to take into account that we are in a global economic crisis, however, this is one of the state's obligations, as is its obligation to have sufficient resources to contain a health problem of these proportions. The second way to answer the question about the possibility of refusal by health 
personnel to care for patients with SARS-Cov-2 virus has to do with the reflection that no one is obliged to do the impossible. ${ }^{16}$ In other words, doctors are walking a path of uncertainty, scientifically they do not have the elements to counteract the pandemic, administratively they do not have the elements, logistically they do not have it, and they do not have how to provide their own biological protection.

Although there is the possibility of establishing protection lawsuits that protect professionals who do not have personal protective equipment not to be forced to fulfill their functions as agents in the first line of care of the pandemic, as shown in the news report from the newspaper El Economista:

"The Supreme Court of Justice of the Nation (SCJN) determined that it is mandatory to provide protective equipment to public health personnel, exposed to the contagion of Covid-19. Faced with several complaints against the Mexican Institute of Social Security (IMSS) and other institutions, the highest court issued a jurisprudence to protect the human capital of the health sector due to the pandemic.

In this way, the Judicial Power will support the doctors, nurses and the rest of the personnel who decide to protect themselves so as not to treat patients with Covid-19 until they are provided with the appropriate personal protective equipment (PPE) to avoid the risk of contagion of the illness. All courts will be obliged to grant protection to those who use this legal resource". ${ }^{17}$

There are not many applications submitted, however, it is worth emphasizing that these few applications for protection $^{18}$ in some states of the Mexican Republic to avoid treating patients affected by COVID-19, they are based on crucial elements such as the fact that they or their families belong to vulnerable groups, ${ }^{19}$ for being responsible for the care of the home, which does not allow them to distance themselves from their homes. Situations where it is necessary to consider the implications of the pandemic humanely. Statistics published by Infobae reports that there are already 584 health professionals who die from COVID-19, so we have 9,023 infected health professionals, of which $58 \%$ are women, $42 \%$ are men, $41 \%$ are nurses, $30 \%$ are doctors, $26 \%$ are health workers, that is, they are dedicated to other hospital areas, $2 \%$ are laboratory workers and $1 \%$ are dentists. There are 1,520 hospitalized health professionals reported as stable, 1,506 reported as serious, 192 remain intubated, 35,814 are outpatients of which $92 \%$ can continue their recovery at home and there were 13,145 suspected cases of contagion, since if the flat number of health professionals that Mexico has are not enough to attend the pandemic.

The statistics are not encouraging at all, since 2015 an average of 2.2 Doctors, nurses and midwives per thousand inhabitants have been reported, ${ }^{20}$ which allows us to think that the number of health professionals is limited in a society like ours and if they continue to face an incentric panorama that calls into question their lives, the possibilities of restitution of health will remain in the hands of awareness collective, a strategy that to date has not shown positive effects for containing the pandemic. Evenwith the uncertainty of this panorama, there are also cases where the medical team acquires this personal protective equipment, with their own resources, there are medical personnel who agree to live far from their families to minimize the risks of contagion, there are those who despite the lack of equipment and material, they constantly investigate and find alternatives that mitigate the effects of this disease. What would allow us to infer that the obligation to provide clinical services, by health professionals, in times of health crisis is indeed a matter that transcends the obligation of adherence to compliance with the norm, is a moral commitment. ${ }^{21-35}$

\section{Conclusion}

Pandemics expose the strengths and weaknesses of people, economic systems and especially health systems. It is important to understand that health policies aimed at protecting society must be based on scientific and ethical criteria, promoting constant legitimation of what is the greatest benefit. The consensus in the implementation of these principles and values for ethical decision-making in adverse situations will allow the optimization and streamlining of the process, the weighting of objective elements for decision-making and will provide support for the weighing of moral stress in personnel health is triggered. The health crisis caused by the COVID-19 pandemic has exposed the difficulty of defining health, economic and social priorities, this situation becomes more critical if the limitation of human and material resources is added to meet clinical needs of the population, this translates into the insufficient number of health professionals assigned to public and private services, the shortage of personal protective equipment, as well as the equipment required for life support in critical conditions.

In times of pandemic, the prevalence of public (or generalized) interest over it will be the axis of reflection and action. The consideration of health professionals as biopsychosocial beings is lost from sight given the individualization of the benefits that this brings, however, we must not lose sight of their vulnerability and their duties as members of a family and a social context. In this sense, in the work of health professionals and the people who make up medical teams, they have a colossal responsibility in their hands and based on this we are tempted to visualize them as superheroes, losing sight of the fact that they are human beings with technical and scientific knowledge necessary to save lives, risking theirs to save ours. Health Professionals have a double configuration that is essential to recognize. The first is the formation of a sufficient professional profile so that the health and life of others and the human facet that makes them as susceptible to diseases, fear and uncertainty as any other person can be deposited in them.

Although the obligation to fulfill their functions as doctors is regulated by civil, administrative and health law, there is no legal provision that affirms that their functions are unlimited and that it is their obligation to always be, and in front of any case. It is true that there are regulations in the face of contingencies where the demand for commitment is greater, there is also in the spirit of medical training a moral imperative (motivated only by the vocation of service) to attend to those who need it.

"If the oath be fulfilled in its entirety, may I live happily and reap the fruits of my art and be honored by all men and by the remotest posteriority. But if I am a transgressor and perjurer, avenge me the opposite...".

\section{Acknowledgments}

None.

\section{Conflicts of interest}

The author declares there is no conflict of interest.

\section{References}

1. https://coronavirus.jhu.edu/map.html

2. The world as we know it will stop. The planes will stop flying. Would you get on a plane with 250 people you don't know, coughing and sneezing, if you knew that some of them could carry a disease that could kill you and for which there are no antivirals or vaccines? "Larry Brillant, American epidemiologist. 2020. 
3. Royal Spanish Academy, Dictionary of the Spanish language. $23^{\text {rd }} \mathrm{edn}$.

4. Ferrater Mora, Jose. Dictionary of Philosophy. Volume Ii L - Z Editorial Sudamerican A Buenos Aires. 2020. p. 569.

5. Carrillo FLM. The Professional Responsibility of the Physician in Mexico. Ed. Porrúa. SA de CV, 2005. p. 1-7.

6. BBC World. In various countries there have been attacks or insults against health workers: cases in which they are prevented from accessing public transport and even their home ormunicipality. 2020.

7. Spanish Collegiate Medical Organization. Code of Medical Deontology. Medical Ethics Guide. p. 15.

8. The Lancet, Editorial. COVID-19: Protecting health-care workers. 2020 p. $1-1$.

9. A total of 39 thousand 32 health professionals have tested positive for a SARS-CoV2 virus contagion and 584 are reported as deceased since the beginning of the pandemic in Mexico and until June 23. 2020.

10. https://www.infobae.com/america/mexico/2020/06/24/ya-son-584-losprofesionales-de-la-salud-que-falleieron-por-covid-19/

11. Jaeger W, Paideia. Fund of Economic Culture; "Greek medicine, considered as Paideia. 1992;55(1):783.

12. Pellegrino ED. Toward a virtue-based normative ethics for the health professions. Kennedy Inst Ethics J. 1995;5(3):253-277.

13. Federal Criminal Code, Second Book, Twelfth Title - Professional Responsibility. Chapter I - General Provisions. Article 229. The previous article shall apply to doctors who, having granted responsibility to take charge of the care of an injured or sick person, abandon him in his treatment without just cause, and without giving immediate notice to the corresponding authority. 2020.

14. Charter of the General Rights of Physicians. Health Secretary. Journal of the Mexican Association of Critical Medicine and Intensive Therapy. 2002;51(5):173-177.

15. Ibid.

16. SÁNCHEZ Gerardo. El Vigía newspaper. 2020

17. https://www.eleconomista.com.mx/politica/SCJN-blinda-a-personalmedico-deben-darles-proteccion-ante-Covid-20201018-0088.html

18. https://noticieros.televisa.com/ultimas-noticias/trabajadores-de-salud-seamparan-para-no-trabajar-por-covid/
19. http://www.hidrocalidodigital.com/logran-licencia-para-regresar-a-suhogar-y-no-arriesgar-a-su-familia/

20. Information recovered from the graph of Dr. Jorge Alberto Alvarez Diaz, Researcher at the UAM Xochimilco Unit, in his presentation "Criteria for admission to the ICU and comments on the" Bioethics Guide.

21. Alvarez Díaz, Jorge Alberto. Presentation "Criteria for admission to the ICU and comments on the" Bioethics Guide".

22. BBC World. In various countries there have been attacks or insults against health workers: cases in which they are prevented from accessing public transport and even their home or municipality. 2020.

23. Carrillo FLM. The Professional Responsibility of the Physician in Mexico. Ed. Porrúa. SA de CV, 2005. p. 1-7.

24. Federal penal code.

25. CONAMED. Charter of the General Rights of Patients December. 2001.

26. DOF: 03/31/2020. AGREEMENT establishing extraordinary actions to address the health emergency generated by the SARS-CoV2 virus.

27. Ferrater Mora, Jose. Dictionary of Philosophy Volume Ii L - Z Editorial Sudamerican A Buenos Aires. p. 569.

28. http://www.hidrocalidodigital.com/logran-licencia-para-regresar-a-suhogar-y-no-arriesgar-a-su-familia/

29. https://coronavirus.jhu.edu/map.html

30. https://noticieros.televisa.com/ultimas-noticias/trabajadores-de-salud-seamparan-para-no-trabajar-por-covid/

31. https://www.eleconomista.com.mx/politica/SCJN-blinda-a-personalmedico-deben-darles-proteccion-ante-Covid-20201018-0088.html

32. https:/www.forbes.com.mx/noticias-larry-brillant-el-epidemiologo-quepredijo-la-pandemia-de-covid-19-hace-14-anos/

33. https://www.infobae.com/america/mexico/2020/06/24/ya-son-584-losprofesionales-de-la-salud-que-falleieron-por-covid-19/

34. Jaeger W. Paideia. Fund of Economic Culture; L IV, ch. I p. 783, "Greek medicine, considered as Paideia". 1992.

35. Johns Hopkins Coronavirus Resource Center. 